\title{
Matrix isolation with an ion transfer device for interference-free simultaneous spectrophotometric determinations of hexavalent and trivalent chromium in a flow-based system
}

Shin-Ichi Ohira ${ }^{a, *}, K^{,}$oretaka Nakamura ${ }^{a}$, Mitsuki Chiba ${ }^{a}$, Purnendu K. Dasgupta ${ }^{b}$, Kei Toda $^{a}$

${ }^{a}$ Department of Chemistry, Kumamoto University, 2-39-1 Kurokami, Chuo-ku, Kumamoto 860-8555, Japan

${ }^{b}$ Department of Chemistry and Biochemistry, University of Texas at Arlington, 700 Planetarium Place, Arlington, TX 76019 USA

*Corresponding author: Shin-Ichi Ohira

E-mail address: ohira@sci.kumamoto-u.ac.jp

TEL: +81-96-342-3384 


\begin{abstract}
Chromium speciation by spectrophotometric determination of hexavalent chromium $(\mathrm{Cr}(\mathrm{VI}))$ with diphenylcarbazide (DPC) has several problems. These include: (1) the inability to directly detect trivalent chromium (Cr(III)) with DPC, (2) positive interference in $\mathrm{Cr}(\mathrm{VI})$ determination by other metal cations and (3) negative interference by any reducing agent present in the sample. These are addressed with an ion transfer device (ITD) in a flow injection analysis system. We previously developed the ITD for electrodialytic separations. Here we separate oppositely charged $\mathrm{Cr}(\mathrm{III})$ and $\mathrm{Cr}(\mathrm{VI})$ species by the ITD into two different acceptor solutions within $\sim 5 \mathrm{~s}$. The acceptor solutions consist of buffered $\mathrm{H}_{2} \mathrm{O}_{2}$ to oxidize the $\mathrm{Cr}(\mathrm{III})$ to $\mathrm{Cr}(\mathrm{VI})$. Then DPC is added to either acceptor to measure $\mathrm{Cr}(\mathrm{III})$ and $\mathrm{Cr}(\mathrm{VI})$ spectrophotometrically. The system was optimized to provide the same response for $\mathrm{Cr}(\mathrm{VI})$ and $\mathrm{Cr}(\mathrm{III})$ with limits of detection (LODs, $\mathrm{S} / \mathrm{N}=3$ ) of $0.5 \mu \mathrm{g} \mathrm{\textrm {L } ^ { - 1 }}$ for each and a throughput rate of 30 samples $\mathrm{h}^{-1}$. The ITD separation was also effective for matrix isolation and reduction of interferences. Potential cationic interferences were not transferred into the anionic $\mathrm{Cr}(\mathrm{VI})$ acceptor stream. Much of the organic compounds in soil extracts were also eliminated as evidenced from standard addition and recovery studies.
\end{abstract}

Key words: Electrodialysis, chromium, diphenylcarbazide, spectrophotometry, soil extracts, flow injection analysis 


\section{Introduction}

Spectrophotometric chromium (Cr) determination with 1,5 - diphenylcarbazide (DPC) is widely used.

Environmental $\mathrm{Cr}$ exists either as cationic trivalent $\mathrm{Cr}(\mathrm{III})$, an essential nutrient, or anionic hexavalent $\mathrm{Cr}(\mathrm{VI})$, a class I carcinogen as defined by International Agency for Research on Cancer (IARC). The DPC method, now more than a century old [1], can measure toxic $\mathrm{Cr}(\mathrm{VI})$ selectively, sensitively, and rapidly. It is approved as a standard method in many countries, e.g., in Japan and the United States. The standard procedure involves batch analysis, the filtered sample solution is mixed with strongly acidic DPC and the absorbance is then measured (typically at 540 $\mathrm{nm})$. The exact reaction pathway of DPC with $\mathrm{Cr}(\mathrm{VI})$ has never been unequivocally established but it is believed that the DPC is oxidized by $\mathrm{Cr}(\mathrm{VI})$ to diphenylcarbazone, which then reacts with the concomitantly produced $\mathrm{Cr}$ (III) to form the observed colored product [2]. In any case, the reaction is rapid at elevated temperature and the colored product formed is stable.

The DPC chemistry has been adapted to the flow analysis format [3]. Sensitivity improvements have been achieved by a long path flow cell [4-6], solid phase spectrometry [7] and thermal lens spectrometry [8]. Oxidation with $\mathrm{Ce}$ (IV) [9-11], $\mathrm{H}_{2} \mathrm{O}_{2}$ [12] or deep UV light [13,14] have been used for conversion of $\mathrm{Cr}$ (III) to $\mathrm{Cr}$ (VI). Determination after such oxidation gives total $\mathrm{Cr}\left(\left[\mathrm{Cr}_{\mathrm{T}}\right]=[\mathrm{Cr}(\mathrm{III})]+[\mathrm{Cr}(\mathrm{VI})]\right)$ from which $\mathrm{Cr}(\mathrm{VI})$, determined without any oxidation, was used to calculate $\mathrm{Cr}(\mathrm{III})$ by subtraction. Such subtraction procedures are susceptible to large errors when the $\mathrm{Cr}(\mathrm{VI})$ concentration is much larger than that of $\mathrm{Cr}(\mathrm{III})$. In the same vein, DPC-based measurement of [Cr(VI)], along with atomic spectrometric measurement of $\mathrm{Cr}_{\mathrm{T}}$ has also been used [15].

Because $\mathrm{Cr}(\mathrm{III})$ and $\mathrm{Cr}(\mathrm{VI})$ are oppositely charged, solid phase extraction (SPE) with ion exchangers that selectively sorb $\mathrm{Cr}(\mathrm{III})$ or $\mathrm{Cr}(\mathrm{VI})$ can be exploited to selectively measure either or both; DPC chemistry can still be used if the $\mathrm{Cr}(\mathrm{III})$ is oxidized to $\mathrm{Cr}(\mathrm{VI})$ after elution [16]. Similar strategies are possible with atomic spectrometric techniques as the measurement method; the general area of Cr speciation with SPE has been reviewed [17,18]. Some exotic sorbents for highly selective Cr species collection have also been reported [19,20]. The latter are not commercially available, however, the essential problem with ion exchange based selective sorption is that either $\mathrm{Cr}(\mathrm{III})$ or $\mathrm{Cr}(\mathrm{VI})$ occurs in real samples in traces with far larger amounts of other ions; ion exchange capacity is often insufficient, especially for saline samples. In addition, prior sample pretreatment including $\mathrm{pH}$ adjustment, are typically necessary for applying SPE-based methods.

We have previously reported on electrodialytic matrix isolation/preconcentration for ionic solutes using an Ion Transfer Device (ITD) [21]. While cationic and anionic species are quantitatively transferred to oppositely placed individual acceptor streams by the applied electric field, non-ionic compounds, low mobility species like proteins, and particulate matter are not transferred and are wasted together with the depleted sample. Electrodialytic matrix isolation was demonstrated to be of utility in the determination of anionic species like carboxylic acids [22] and cationic species like heavy metal ions [23] in real samples. Furthermore, the electrodialytic matrix isolation

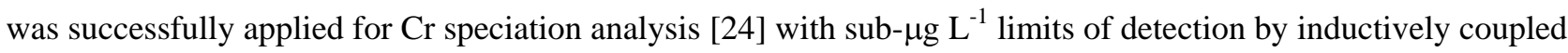
plasma- mass spectrometry (ICP-MS).

While it is hard to do any better in terms of LODs and the sample throughput rate than the ICP-MS adaptation of the ITD, an ICP-MS is very expensive to own, operate and maintain and is not accessible to all. In the present study, we fully optimize the use of ITD based Cr speciation with DPC-based measurement, with special attention to 
matrix isolation and interference in $\mathrm{Cr}(\mathrm{VI})$ measurements by metal cations [25-28] and anions [29,30]. Soil extracts were successfully analyzed for $\mathrm{Cr}(\mathrm{VI})$ by this approach.

\section{Experimental}

\subsection{Reagents}

All reagents were obtained from www.nacalai.co.jp or www.wako-chem.co.jp. Ultrapure water (Milli $\mathrm{Q}^{\mathrm{TM}}$ www.emdmillipore.com) was used in all experiments. Standard solutions of $\operatorname{Cr}(\mathrm{III})$ and $\mathrm{Cr}(\mathrm{VI})$ were prepared in 1 mM HNO 3 with $\mathrm{CrCl}_{3} \cdot 6 \mathrm{H}_{2} \mathrm{O}$ and $\mathrm{K}_{2} \mathrm{CrO}_{4} \cdot 6 \mathrm{H}_{2} \mathrm{O}$, respectively. Trace Element Analysis grade $\mathrm{HNO}_{3}$ was used throughout the experiments. The DPC reagent was prepared by dissolving DPC $(0.3 \mathrm{~g})$ in acetone $(10 \mathrm{~mL})$ and diluting to $500 \mathrm{~mL}$ with $0.2 \mathrm{M} \mathrm{H}_{2} \mathrm{SO}_{4}$. The carrier/oxidizer, $7.5 \mathrm{mM} \mathrm{H}_{2} \mathrm{O}_{2}$ in $\mathrm{pH} 8.5$ borate buffer, was prepared by adding $\mathrm{H}_{2} \mathrm{O}_{2}\left(0.43 \mathrm{~mL}, 30 \%\right.$ w/v) into borate buffer $\left(500 \mathrm{~mL}\right.$, $\mathrm{pH} 8.5 ; 1.35 \mathrm{~g}^{\circ} \mathrm{H}_{3} \mathrm{BO}_{3}$ in $500 \mathrm{~mL}$ water, $\mathrm{pH}$ adjusted with $\mathrm{KOH})$. Metal ion standards for the interference study were prepared with $\mathrm{NiCl}_{2} \cdot 6 \mathrm{H}_{2} \mathrm{O}, \mathrm{CoCl}_{2} \cdot 6 \mathrm{H}_{2} \mathrm{O}$, $\mathrm{ZnCl}_{2}, \mathrm{MnCl}_{2} \cdot 4 \mathrm{H}_{2} \mathrm{O}, \mathrm{Pb}\left(\mathrm{NO}_{3}\right)_{2}, \mathrm{FeCl}_{3} \cdot 6 \mathrm{H}_{2} \mathrm{O}, \mathrm{CuCl}_{2} \cdot 2 \mathrm{H}_{2} \mathrm{O}, \mathrm{NH}_{4} \mathrm{VO}_{3}$, and $\left(\mathrm{NH}_{4}\right)_{6} \mathrm{Mo}_{7} \mathrm{O}_{24} \cdot 4 \mathrm{H}_{2} \mathrm{O}$.

\subsection{Ion transfer device}

Details of the ITD structure were previously reported [23, 26]. The schematic diagram is in Fig. 1a. Five solution layers were stacked vertically, separated by appropriate membranes that allow passage of ions. The sample is introduced into the center channel while acceptor channels, separated respectively by cation and anion exchange functionality modified regenerated cellulose membrane (CFDM and AFDM, see [24, 26]) flank the sample channel on the top and bottom. The outermost channels, called isolator channels serve to prevent direct electrode contact (and hence any redox conversion) of the acceptor channel contents. The outermost channels are furnished with Pt screen electrodes (0.07 mm wire diameter, 100 mesh, www.nippon-clever.co.jp). The cation/anion acceptor and cathode/anode isolator channels were separated by anion and cation exchange membranes (AEM and CEM, Selemion ${ }^{\circledR}$ DSV and CMV, www.agc.com), respectively. The channels themselves were prepared by pressing Parafilm® on nylon screen (150 mesh, thickness $106 \mu \mathrm{m}$, www.nippon-clever.co.jp). The dimensions of the flow-through portion of each channel were $5 \mathrm{~mm}$ width $\times 40 \mathrm{~mm}$ length $\times 0.13 \mathrm{~mm}$ height. Isolator channels were machined with $0.2 \mathrm{~mm}$ depth on the top and bottom PVC plates.

Peristaltic pumps were used for pumping sample, carrier, and isolator solutions while syringe pumps were used for acceptor solutions. Accurate flow rates are essential for sample and acceptor solutions. However, chromium species, especially $\mathrm{Cr}(\mathrm{III})$, is easily adsorbed on the glass syringe surface. The sample solution was therefore pumped peristaltically with Pharmed ${ }^{\circledR}$ pump tubes. Sample/carrier and acceptor solutions (all $10 \mathrm{mM}$ $\mathrm{HNO}_{3}$ ) were pumped at $0.20 \mathrm{~mL} \mathrm{~min}^{-1}$ and isolator solutions $\left(30 \mathrm{mM} \mathrm{HNO}_{3}\right.$ ) were pumped at $3 \mathrm{~mL} \mathrm{~min}^{-1}$. A constant $15 \mathrm{~V}$ DC was applied between the electrodes. The flow rates, concentrations, and applied voltage has been optimized as previously described [26]. The anode and cathode acceptor solutions were individually introduced into the flow injection analysis system. 


\subsection{DPC based flow analysis system}

Chromium in either ITD acceptor effluent was determined with the flow injection analysis system based on DPC chemistry (Fig. 1b). Automated sample injectors (Cheminert C22Z-3186D, www.vici.com, included $50 \mu \mathrm{L}$ loop) each for $\mathrm{Cr}(\mathrm{III})$ and $\mathrm{Cr}(\mathrm{VI})$ were serially placed in the carrier stream of buffered $\mathrm{H}_{2} \mathrm{O}_{2}$. The stream next flowed through a heated reaction coil $\left(60{ }^{\circ} \mathrm{C}, 400 \mu \mathrm{L}\right.$, nominal $\left.t_{R} 30 \mathrm{~s}\right)$ to complete the oxidation by hydrogen peroxide and was then merged with the acidic DPC reagent flow and followed by another reaction coil $\left(60^{\circ} \mathrm{C}, 350 \mu \mathrm{L}\right.$, nominal $t_{R} 13 \mathrm{~s}$ ) and then through an absorbance detector (Spectroflow 757, Kratos) set at $540 \mathrm{~nm}$. All system tubing, including the heated reactors, were composed of $0.5 \mathrm{~mm}$ i.d. $1.6 \mathrm{~mm}$ o.d. PEEK tubing (www.glscience.com); PEEK has approximately the same thermal conductivity $(0.25 \mathrm{~W} / \mathrm{m} \mathrm{K})$ as the more commonly used PTFE but shows less adsorption of the DPC reaction product). The two heated coils were part of an integrated arrangement that consisted of the two tubular reactors, a heating element and a thermocouple (621-2158, http://jp.rs-online.com/ ) all potted in a block of low-melting bismuth-tin alloy (Wood's metal) [31].

For soil extract measurement, the Japanese standard method measures only $\mathrm{Cr}(\mathrm{VI})$. The extraction conditions uses $\mathrm{pH}$ 5.8-6.3. To detect $\mathrm{Cr}(\mathrm{VI})$ only, the FIA system was simplified by omitting the $\mathrm{Cr}(\mathrm{III})$ injector and the oxidation reactor (components in the dotted enclosure) in Fig. 1b. The carrier and the anode acceptor solutions were both $10 \mathrm{mM} \mathrm{HNO}_{3}$.

\subsection{Preparation of soil extract}

Soil samples used in the present work came from near the Shirakawa river (Kumamoto, Japan) in winter from three locations: (a) under a tree, (b) grassy lawn, and (c) playground. The samples were treated following prescribed Japanese environment agency protocols [32]: The collected samples were equilibrated overnight in a constant humidity environment (20\%RH, SD-3, www.as-1.co.jp). After removing large particles by passing through a 2-mm sieve, $500 \mathrm{~mL}$ water was added to $50 \mathrm{~g}$ sample and the $\mathrm{pH}$ of the stirred suspension was adjusted to 6 with dilute $\mathrm{HCl}$. The mixture was placed in a 1-L plastic bottle and shaken on a mechanical shaker (200 oscillations per minute) for $6 \mathrm{~h}$. The mixture was allowed to settle for $20 \mathrm{~min}$ and an aliquot of the supernatant then centrifuged for $20 \mathrm{~min}$ at 3,000 rpm (SPN-400, www.shimadzu.com). The clear supernatant was filtered through a $0.45 \mu \mathrm{m}$ PTFE filter and the filtrate analyzed by the present system. The spectra of the filtrate in quartz cuvettes were also measured with a double beam UV-VIS spectrophotometer (UV-3600, www.shimadzu.com).

\section{Results and Discussion}

\subsection{Optimization for simultaneous FIA analysis of $\mathrm{Cr}(\mathrm{III})$ and $\mathrm{Cr}(\mathrm{VI})$}

In the present study, both forms of Cr were measured with DPC chemistry. As $\mathrm{Cr}$ (III) does not react with DPC, an oxidation procedure is required. We considered the three different oxidants that have mainly been used for this purpose: $\mathrm{Ce}(\mathrm{IV})$ [11], deep-UV radiation [13, 14], and $\mathrm{H}_{2} \mathrm{O}_{2}[12,16]$. Oxidation with $\mathrm{Ce}(\mathrm{IV})$ requires acidic conditions, under these conditions, $\mathrm{Cr}(\mathrm{VI})$ formed also functions as an oxidant and can be lost by reaction with slowly oxidized material such as organic acids [11] that may be present in a soil extract. Oxidation with UV-radiation was particularly attractive because no reagent is involved. However, when a $\mathrm{Cr}(\mathrm{III})$ standard (1 mg 
$\mathrm{L}^{-1} \mathrm{Cr}(\mathrm{III})$ in $0.1 \mathrm{M} \mathrm{HNO}_{3}$ ) flowing through a planar channel $(8 \mathrm{~mm}$ width $\times 50 \mathrm{~mm}$ length $\times 0.125 \mathrm{~mm}$ depth $)$ at $0.2 \mathrm{~mL} / \mathrm{min}$ (nominal $t_{R} 15 \mathrm{~s}$ ) was irradiated via a quartz window with a Hg pen lamp (manufacture specified radiant flux $30 \mu \mathrm{W} / \mathrm{cm}^{2} @ 30 \mathrm{~cm}$ from source, P/N 81-1025-01,www.bhkinc.com) placed immediately atop, the conversion efficiency was only $54 \%$. The UV oxidation efficiency depends on the solution $\mathrm{pH}$; quantitative conversion has been reported at $\mathrm{pH} 3.2$ [14]. However, any need to adjust $\mathrm{pH}$ decreases sample throughput and formation of $\mathrm{Cr}(\mathrm{VI})$ under acidic condition will make it susceptible to reduction by any oxidizables present. Also, considering that real samples will have other and varying amounts of UV absorbing substances, this did not seem to be a practical approach without performing standard addition. On the other hand, $\mathrm{H}_{2} \mathrm{O}_{2}$ could convert from $\mathrm{Cr}(\mathrm{III})$ to $\mathrm{Cr}(\mathrm{VI})$ quantitatively under mildly alkaline conditions in which $\mathrm{Cr}(\mathrm{VI})$ is not a strong oxidant and is not easily lost. The $\mathrm{H}_{2} \mathrm{O}_{2}$ concentration optimization result appear in Fig. 2a. The standard solutions (50 $\mu \mathrm{g} \mathrm{L}^{-1}$ each) were directly introduced into the sample loops. With $10 \mathrm{mM} \mathrm{HNO}_{3}$ as the carrier, essentially only $\mathrm{Cr}(\mathrm{VI})$ responded (left panel, Fig. 2a). But with $\mathrm{H}_{2} \mathrm{O}_{2}$ in a pH 8.5 borate buffer the conversion of $\mathrm{Cr}$ (III) to $\mathrm{Cr}(\mathrm{VI})$ started and the highest value was obtained with $6.0 \mathrm{mM} \mathrm{H}_{2} \mathrm{O}_{2}$. Note that at higher $\mathrm{H}_{2} \mathrm{O}_{2}$ concentrations the response decreases and even at the optimum $6.0 \mathrm{mM} \mathrm{H}_{2} \mathrm{O}_{2}$ the response of $\mathrm{Cr}(\mathrm{VI})$ is $\sim 15 \%$ less than that with a $10 \mathrm{mM} \mathrm{HNO}_{3}$ carrier. This is because after acidification with the DPC reagent some $\mathrm{Cr}(\mathrm{VI})$ can be lost by $\mathrm{H}_{2} \mathrm{O}_{2}$ acting as a reductant and this loss is dependent on the residual $\mathrm{H}_{2} \mathrm{O}_{2}$ concentration. While others have suggested a carbonate buffer [16] as the medium for the $\mathrm{H}_{2} \mathrm{O}_{2}$ oxidation of $\mathrm{Cr}(\mathrm{III})$, this is incompatible with the present system because of formation of $\mathrm{CO}_{2}$ bubbles after addition of the acidic DPC solution.

The reaction temperature was also optimized. In the present study, reactors for oxidation and color development were integrated into one heated block. Around room temperature $\left(20^{\circ} \mathrm{C}\right)$, the $\mathrm{Cr}(\mathrm{III})$ response was less compared to that of $\mathrm{Cr}(\mathrm{VI})$. However, the two became equal at $40{ }^{\circ} \mathrm{C}$ (see the green trace in Figure $2 \mathrm{~b}$ for the response ratio) and remained equivalent until $80{ }^{\circ} \mathrm{C}$, the highest temperature studied. However, the absolute response increased until $60^{\circ} \mathrm{C}$ and did not increase further thereafter. A reactor temperature of $60{ }^{\circ} \mathrm{C}$ was henceforth chosen.

\subsection{Response characteristics}

The acceptor effluents from the ITD were injected into the optimized FIA system. The system output for $10 \mu \mathrm{g} \mathrm{L}^{-1}$ $\mathrm{Cr}(\mathrm{III}), 10 \mu \mathrm{g} \mathrm{L}{ }^{-1} \mathrm{Cr}(\mathrm{VI})$, and a mixture containing $10 \mu \mathrm{g} \mathrm{L}{ }^{-1}$ of each introduced into the ITD is shown in Fig. 3. The ITD could quantitatively transfer the $\mathrm{Cr}(\mathrm{III})$ and $\mathrm{Cr}(\mathrm{VI})$ into the different acceptor solutions. The first peak is absent if there was no $\mathrm{Cr}(\mathrm{VI})$ and similarly, the second peak was absent if there was only $\mathrm{Cr}(\mathrm{VI})$. The responses for $\mathrm{Cr}(\mathrm{III})$ and $\mathrm{Cr}(\mathrm{VI})$ were statistically equivalent: peak heights for $10 \mu \mathrm{g} \mathrm{L}{ }^{-1}$ of $\mathrm{Cr}(\mathrm{III})$ and $\mathrm{Cr}(\mathrm{VI})$ were $3.93 \pm 0.04$ and 3.97 $\pm 0.03 \mathrm{mAU}$, respectively $(n=3)$. Calibration behavior was studied with the mixed standards up to concentrations of $50 \mu \mathrm{g} \mathrm{L}^{-1}$ each; a response FIAgram is also shown in Fig. 3. The calibration equations were:

$\mathrm{Cr}$ (III) Peak height, $\mathrm{mAU}=(0.405 \pm 0.008) \times\left[\mathrm{Cr}(\mathrm{III}), \mu \mathrm{g} \mathrm{L}^{-1}\right]-(0.18 \pm 0.23)$

$\mathrm{Cr}(\mathrm{VI})$ Peak height, $\mathrm{mAU}=(0.406 \pm 0.007) \times\left[\mathrm{Cr}(\mathrm{III}), \mu \mathrm{g} \mathrm{L} \mathrm{L}^{-1}\right]-(0.14 \pm 0.22)$ 
Limits of detection based on the $\mathrm{S} / \mathrm{N}=3$ criterion were both $0.5 \mu \mathrm{g} \mathrm{L}{ }^{-1}$ for $\mathrm{Cr}(\mathrm{III})$ and $\mathrm{Cr}(\mathrm{VI})$. Independent measurement of $\mathrm{Cr}$ species as carried out here will produce more accurate results compared to subtraction-based approaches.

\subsection{Interferences}

Interference by many cationic heavy metals in DPC-based determination of $\mathrm{Cr}(\mathrm{VI})$ is well documented [4, 25-30]. Interference studies were performed with the several kinds of metal cations and oxometal anions for the present system. Figure 4 shows that cationic metals $\mathrm{Fe}^{3+}, \mathrm{Cu}^{2+}, \mathrm{Mn}^{2+}, \mathrm{Co}^{2+}, \mathrm{Ni}^{2+}, \mathrm{Zn}^{2+}$ and $\mathrm{Pb}^{2+}$ at the $10 \mathrm{mg} \mathrm{L}^{-1}$ level had no discernible effects on the response of $10 \mu \mathrm{g} \mathrm{L}^{-1} \mathrm{Cr}(\mathrm{VI})$. This is understandable as the cations are not collected in the anode acceptor where the $\mathrm{Cr}(\mathrm{VI})$ ends up. Without the ITD, $\mathrm{Cu}^{2+}$ interferes at concentrations as low as $1 \mathrm{mg} \mathrm{L}^{-1}$ and $\mathrm{Fe}^{3+}$ interferes by $5 \mathrm{mg} \mathrm{L}^{-1}$. Importantly vanadate and molybdate are oxometallates just like $\mathrm{Cr}(\mathrm{VI})$ and end up together with $\mathrm{Cr}(\mathrm{VI})$. Tolerance to these ions is limited; while there is no effect at $100 \mu \mathrm{g} \mathrm{L}^{-1} \mathrm{~V}$ or Mo, there is a discernible interference at concentrations $\geq 1 \mathrm{mg} \mathrm{L}^{-1}$. The concentration of these ions in drinking water and soil extracts has been reported to be in the range of 0.003 0.54 and 0.06 22.7 $\mathrm{mg} \mathrm{L}^{-1}$ for $\mathrm{V}$ and Mo, respectively $[33,34]$. Realistically, the interference from vanadate is not therefore likely to be significant. We also found in batch experiments that the DPC-vanadate product is unstable with time. For example, $1 \mathrm{mg} \mathrm{L}^{-1} \mathrm{~V}$ as vanadate caused a $+12.5 \%$ interference in the measurement of $250 \mu \mathrm{g} \mathrm{L}{ }^{-1} \mathrm{Cr}$. After $15 \mathrm{~min}$, this decreased to a $+5 \%$ interference. If high $\mathrm{V}$ is an issue, a stopped-flow approach where the peak apex is arrested in the cell and a decrease in absorbance with time is monitored (and projected to completion) will be worthy of investigation. For Mo, others have reported [35] that the addition of oxalic acid to the DPC reagent formulation as a masking agent eliminates the interference: we have confirmed that this is applicable in the presently proposed system.

For $\mathrm{Cr}(\mathrm{III})$ measurement, $\mathrm{Fe}^{3+}$ and $\mathrm{Cu}^{2+}$ interfered above 5 and $1 \mathrm{mg} \mathrm{L}^{-1}$, respectively, none of the other metal species studied interfered.

\subsection{Matrix isolation for soil extract analysis}

An important advantage of the ITD for sample pretreatment is matrix isolation. This is more important to spectrometric measurements than element-specific ICP-MS. The evaluation of the matrix isolation efficiency was studied for the determination of $\mathrm{Cr}(\mathrm{VI})$ in soil extracts.

Chromium in soil leachates need to be analyzed for environmental impact evaluations. Soil extraction methods have been standardized by official agencies in different countries and may differ between countries. The Japanese standard method [32] prescribes extraction with purified water after $\mathrm{pH}$ adjustment to 6 with $\mathrm{HCl}$. The method is for $\mathrm{Cr}(\mathrm{VI})$ determination. At this $\mathrm{pH}, \mathrm{Cr}(\mathrm{VI})$ does not function as oxidant. On the other hand, at this $\mathrm{pH}$ $\mathrm{Cr}(\mathrm{III})$ is not extractable. In preliminary experiments, we have tested spike recoveries of both $\mathrm{Cr}(\mathrm{VI})$ and $\mathrm{Cr}(\mathrm{III})$ added to soil with the present analysis system. The recoveries of $\mathrm{Cr}(\mathrm{IIII})$ was essentially zero. Based on the thermodynamic as well as experimental data, approximately $50 \mu \mathrm{g} \mathrm{Cr} \mathrm{L}^{-1}$ can be dissolved at $\mathrm{pH} 6$ in water [36]. However, at this $\mathrm{pH}$, the carboxylic acid groups in soil humus will be negatively charged and $\mathrm{Cr}(\mathrm{III})$ will be tightly 
bound - $\mathrm{Cr}(\mathrm{III})$ is always far less bioavailable and mobile in soils compared to $\mathrm{Cr}(\mathrm{VI})$ [37]. While $\mathrm{Cr}(\mathrm{III})$ does form fulvic acid complexes (and presumably humic acid complexes), they are retained by ultrafilters [38] and as such will not be considered soluble and are very unlikely to pass through the present dialysis membranes in a short period. Moreover, such complexes will be essentially neutral. We tested low molecular weight organic ligands e.g., ascorbate, glutamate, mandelate, citrate, cysteine, serine, pyruvate and oxalate, considered as possible organic ligands in soil extracts [39]. The fully formed complexes are assumed to be negatively charged. However, when we separately introduced individual $\mathrm{Cr}(\mathrm{III})$ ):ligand mixtures (1:5 molar ratio, containing $1 \mathrm{mg} \mathrm{Cr}(\mathrm{IIII}) \mathrm{L}^{-1}, \mathrm{pH}$ adjusted to 6) into the ITD, no Cr was found in acceptor (+) channel but some $\mathrm{Cr}(\mathrm{III})$, much less than quantitative, was observed in acceptor (-) channel, presumably due to the dissociation of the complex. When $\mathrm{Cr}(\mathrm{III})$-organic complex solutions were directly introduced into FIA system without ITD separation, the response also depended on the particular ligand used, suggesting considerable kinetic differences in the oxidation of various $\mathrm{Cr}(\mathrm{III})$-organic complexes by $\mathrm{H}_{2} \mathrm{O}_{2}$ [40]. Clearly, the quantitative determination of $\mathrm{Cr}(\mathrm{III})$ in its organic complexes as well as their behavior in ITD based separation - determination systems need more study. Presently, we focused on the evaluation of matrix isolation efficiencies for the determination of $\mathrm{Cr}(\mathrm{VI})$ in soil extract.

Soil extract contain many colored organic compounds such as humic acids and often also very fine particulate matter that passes through a $0.45 \mu \mathrm{m}$ filter. Both interfere with the accuracy of low level absorbance measurements. The Japanese industrial standard (JIS) method utilizes a blank measurement in which a small amount of methanol is added to the acidified sample (which then reduces $\mathrm{Cr}(\mathrm{VI})$ to $\mathrm{Cr}(\mathrm{III})$ that does not react with DPC). In the flow analysis literature, blank subtraction where the blank is obtained without DPC addition has been suggested [41]. Another article suggests generation of a blank in-line by adding ascorbic acid to reduce $\mathrm{Cr}(\mathrm{VI})$ to $\mathrm{Cr}(\mathrm{III})$ [42]. All of these approaches involve additional steps. The importance of this blank preparation can be observed in Fig 5a. All three of our filtered soil extract samples had significant absorbance at $540 \mathrm{~nm}$. Sample B that displayed the highest background absorbance would have registered $150 \mu \mathrm{g} \mathrm{L}^{-1} \mathrm{Cr}(\mathrm{VI})$ if this blank was not corrected for. In contrast, in the present study, the ITD essentially eliminated the interference without having to take separate steps to prepare an appropriate blank and subtract (with the attendant problems of subtraction methods). The results of standard addition to the soil extract samples without using the ITD are shown in Fig. 5b.

The relevant equations for the respective samples without ITD treatment were:

$$
\begin{aligned}
& \text { Standard: Abs., mAU }=(0.123 \pm 0.003)[\mathrm{Cr}]+(0.111 \pm 0.003) \\
& \text { Sample A: Abs., mAU }=(0.125 \pm 0.002)[\mathrm{Cr}]+(0.769 \pm 0.054) \\
& \text { Sample B: Abs., mAU }=(0.050 \pm 0.008)[\mathrm{Cr}]+(12.5 \pm 0.231) \\
& \text { Sample C: Abs., mAU }=(0.102 \pm 0.004)[\mathrm{Cr}]+(5.93 \pm 0.128)
\end{aligned}
$$

The equations for the same samples with ITD treatment were:

$$
\begin{aligned}
& \text { Standard : Abs., mAU }=(0.114 \pm 0.003)[\mathrm{Cr}]+(0.405 \pm 0.102) \\
& \text { Sample A: Abs., mAU }=(0.117 \pm 0.003)[\mathrm{Cr}]+(0.314 \pm 0.076) \\
& \text { Sample B: Abs., mAU }=(0.114 \pm 0.004)[\mathrm{Cr}]+(0.802 \pm 0.109) \\
& \text { Sample C: Abs., mAU }=(0.117 \pm 0.003)[\mathrm{Cr}]+(0.632 \pm 0.080)
\end{aligned}
$$


It is not just that large intercepts, as may be expected from the direct spectral absorption measurements, are observed, the greater the amount of the absorbing impurities, the lower is the slope of the best-fit line, suggesting that these absorbing impurities are oxidizable and consume $\mathrm{Cr}(\mathrm{VI})$ and the prescribed blank subtraction methods will not really be effective. The same experiment done with the ITD in contrast led to identical standard addition slopes for all samples and essentially reduced the intercept indistinguishable from that of the standard.

\section{Conclusion}

We have successfully developed a DPC-colorimetry based flow analysis system capable of speciating $\mathrm{Cr}(\mathrm{VI})$ and $\mathrm{Cr}$ (III) using an ITD. No blank subtraction methods are needed in real soil extract samples containing absorbing impurities. Matrix isolation by the ITD could be generally useful for elimination of interference in other ionic solute determinations. The present system can be used in the field. We are presently working on further enhancing the sensitivity and expect this to become an affordable attractive tool for monitoring environmental $\mathrm{Cr}$.

\section{Acknowledgments}

This study was supported partially by Japanese Environment Research and Technology Development Fund (5RF-1602), the Japan Science and Technology, Development of Systems and Technology for Advanced Measurement and Analysis program (SENTAN), and partially by the Steel Foundation for Environmental Protection Technology. Participation of PKD was made possible by a grant from the US National Science Foundation (CHE-1506572). 
[1] A. Moulin, Colorimetric determination of chromium, Bull. Chem. Soc. Paris 31 (1904) 295-296.

[2] R.T. Pflaum, L.C. Howick, The chromium-diphenylcarbazide reaction, J. Am. Chem. Soc. 78 (1956)

$4862-4866$.

[3] S.S. Jørgensen, M.A.B. Regitano, Rapid determination of chromium (VI) by flow injection analysis, Analyst 105 (1980) 292-295.

[4] S. Jambunathan, P. K. Dasgupta, Determination of hexavalent chromium in leather extracts by the diphenylcarbazide (IUC-18) procedure: pitfalls and refinements, J. Soc. Leather Technol. Chem. 84 (2000) 63-73.

[5] Q. Li, K.J. Morris, P.K. Dasgupta, I.M. Raimundo Jr., H. Temkin, Portable flow-injection analyzer with liquid-core waveguide based fluorescence, luminescence, and long path length absorbance detector, Anal. Chim. Acta 479 (2003) 151-165.

[6] J. Ma, D. Yuan, R.H. Byrne, Flow injection analysis of trace chromium (VI) in drinking water with a liquid capillary cell and spectrophotometric detection, Environ. Monit. Assess. 186 (2014) 367-373.

[7] S. Saputro, K. Yoshimura, S. Matsuoka, K. Takehara, Narsito, Improved solid-phase spectrophotometry for the microdetermination of chromium (VI) in natural water, Anal. Sci. 25 (2009) 1445-1450.

[8] A. Mad`zgalj, M.L. Baesso, M. Franko, Flow injection thermal lens spectrometric detection of hexavalent chromium, Eur. Phys. J. Special Topics 153 (2008) 503-506.

[9] M.J. Whitaker, Determination of total chromium by flow injection analysis, Anal. Chim. Acta 174 (1985) 375-378.

[10] J. Ruz, A. Ríos, M.D.L. de Castro, M. Valcárcel, Flow-injection configurations for chromium speciation with a single spectrophotometric detector, Anal. Chim. Acta 186 (1986) 139-146.

[11] J.C. de Andrade, J.C. Rocha, N. Baccan, Sequential spectrophotometric determination of chromium (III) and chromium (VI) using flow injection analysis, Analyst 110 (1985) 197-199.

[12] J.E.T. Anderson, Introduction of hydrogen peroxide as an oxidant in flow injection analysis: speciation of $\mathrm{Cr}(\mathrm{III})$ and $\mathrm{Cr}(\mathrm{VI})$, Anal. Chim. Acta 361 (1998) 125-131.

[13] S. Taguchi, A. Fujii, T. Okoshi, H. Kuramitz, N. Hata, Successive determination of chromium (VI) and total chromium by FIA using photo-oxidation with vacuum ultraviolet, Bunseki Kagaku 59 (2010) 1133-1136.

[14] Sarenqiqige, M. Ashitomi, K. Yoshimura, Anal. Sci. 29 (2013) 823-829.

[15] M. Noroozifar, M. Khorasani-Motlagh, R. Akbari, Application of pneumatic flow injection - tandem spectrometer system for chromium speciation, J. Automat. Methods Manage. Chem. (2007) 34373.

[16] S. Jung, H. Lim, C. Kang, Y. Choi, Spectrophotometric determination of ultra trace tri \& hexavalent chromium by using on-line flow injection analysis with dual preconcentration column, Bull. Kor. Chem. Soc. 32 (2011)

3437-3442.

[17] V. Go'mez, M.P. Callao, Chromium determination and speciation since 2000, TrAC Trends Anal. Chem. 25 (2006) 1006-1015.

[18] K. Pyrzynska, Redox speciation of chromium using sorption-based systems, TrAC Trends Anal. Chem. 32 (2012) 100-112.

[19] Y. Furusho, M. Ono, M. Yamada, T. Kitade, S. Motomizu, Determination of Cr(VI) by solid-phase extraction with highly selective resin, Bunseki Kagaku 58 (2009) 147-152.

[20] S. Paramanik, S. Dey, P. Chattopadhyay, A new chelating resin containing azophenolcarboxylate functionality: synthesis, characterization and application to chromium speciation in wastewater, Anal. Chim. Acta 584 (2007) 469-475.

[21] S. Ohira, K. Kuhara, M. Kudo, Y. Kodama, P.K. Dasgupta, K. Toda, Electrodialytic ion isolation for matrix removal, Anal. Chem. 84 (2012) 5421-5426.

[22] S. Ohira, K. Kuhara, A. Shigetomi, T. Yamasaki, Y. Kodama, P.K. Dasgupta, K. Toda, On-line electrodialytic matrix isolation for chromatographic determination of organic acids in wine, J. Chromatogr. A 1372 (2014) 18-24. [23] S. Ohira, Y. Hiroyama, K. Nakamura, P.K. Dasgupta, K. Toda, Electrodialytic matrix isolation for metal cations, Talanta 132 (2015) 228-233.

[24] S. Ohira, K. Nakamura, C. Phillip Shelor, P.K. Dasgupta, K. Toda, Simultaneous Electrodialytic Preconcentration and Speciation of Chromium(III) and Chromium(VI). Anal. Chem. 87 (2015) 11575-11580

[25] E. van Dalen, S. Balt, The reactions of diphenylcarbazide and diphenyl carabzone with cations, Anal. Chim. Acta 25 (1961) 507-508.

[26] S. Balt, E. van Dalen, The reactions of diphenylcarbazide and diphenylcarbazone with cations part II. Extraction behavior and spectra of the reagents, Anal. Chim. Acta 27 (1962) 188-193.

[27] S. Balt, E. van Dalen, The reactions of diphenylcarbazide and diphenylcarbazone with cations part III. Nature and properties of the mercury complexes, Anal. Chim. Acta 27 (1962) 416-421. 
[28] S. Balt, E. van Dalen, The reactions of diphenylcarbazide and diphenylcarbazone with cations part IV. Cations of Mn, Fe, Co, Ni, Cu, Zn, Cd, Sn and Pb, Anal. Chim. Acta 29 (1963) 466-471.

[29] H. Onishi, H. Koshima, Conditions for the photometric determination of chromium (VI) with diphenylcarbazide and effects of iron and vanadium, Bunseki Kagaku 27 (1978) 726-729.

[30] M. Bose, The reaction of vanadate with diphenylcarbazide, Kurze Originalmitteilungen, 19 (1957) 511-512. [31] J. Li, P.K. Dasgupta, Z. Genfa, M.A. Hutterli, Measurement of atmospheric formaldehyde with a diffusion scrubber and light-emitting diode-liquidcore waveguide based fluorometry, Field Anal. Chem. Technol. 5 (2001) $2-11$.

[32] Ministry of the Environment, Environmental quality standards for soil contamination, No. 46 of Japan Ministry of the Environment Notification. (1976).

[33] G.R. Breadford, D. Bakhtar, Determination of trace metals in saline irrigation drainage waters with inductively coupled plasma optical emission spectrometer after preconcentration by chelation-solvent extraction, Environ. Sci. Technol. 25 (1991) 1704-1708.

[34] H. Malassa, F. Al-Rimawi, M. Al-Knatib, M. Al-Qutob, Determination of trace heavy metals in harvested rainwater used for drinking in Hebron (south West Bank, Palestine) by ICP-MS, Environ. Monit. Assess 186 (2014) 6985-6992.

[35] F. Feigl, V. Anger, Spot Tests in Inorganic Analysis $6^{\text {th }}$ ed.,Elsevier Science, 1972, p. 191.

[36] D. Rai, B.M. Sass, D.A. Moore, Chromium(III) hydrolysis constants an solubility of chromium (III) hydroxide, Inorg. Chem. 26 (1987) 345-349.

[37] G. Choppala, N. Bolan, D. Lamb, A. Kunhikrishnan, Comparative sorption and mobility of Cr(III) and Cr(VI) species in a range of soils: implications to bioavailability, Water Air Soil Pollut 224 (2013) 1699.

[38] M. Krajnc, J. Štupar, S. Milićev, Characterization of chromium and copper complexes with fulvic acids isolated from soils in Slovenia. Sci. Tot. Environ. 159 (1995) 23-31.

[39] Z. Luo, A. Wadhawan, E.J. Bouwer, Sorption behavior of nine chromium (III) organic complexes in soil, Int. J. Environ. Sci. Tech. 7 (2010) 1-10.

[40] Z. Luo, N. Chatterjee, Kinetics of oxidation of $\mathrm{Cr}(\mathrm{III})$-organic complexes by $\mathrm{H}_{2} \mathrm{O}_{2}$, Chem. Speciation Bioavailability 22 (2010) 25-34.

[41] M.Tatsumi, S. Ozaki, E. Nakamura, Determination of chromium (VI) by two-channel flow injection analysis system using dilute acetone-based diphenylcarbazide system, Bunseki Kagaku 62 (2013) 31-35.

[42] T. Yamane, T. Murayama, T. Murata, T. Kawai, Rapid and simple determination of chromium (VI) in the leached solution from soil by FIA, Bunseki Kagaku 51 (2002) 311-315. 

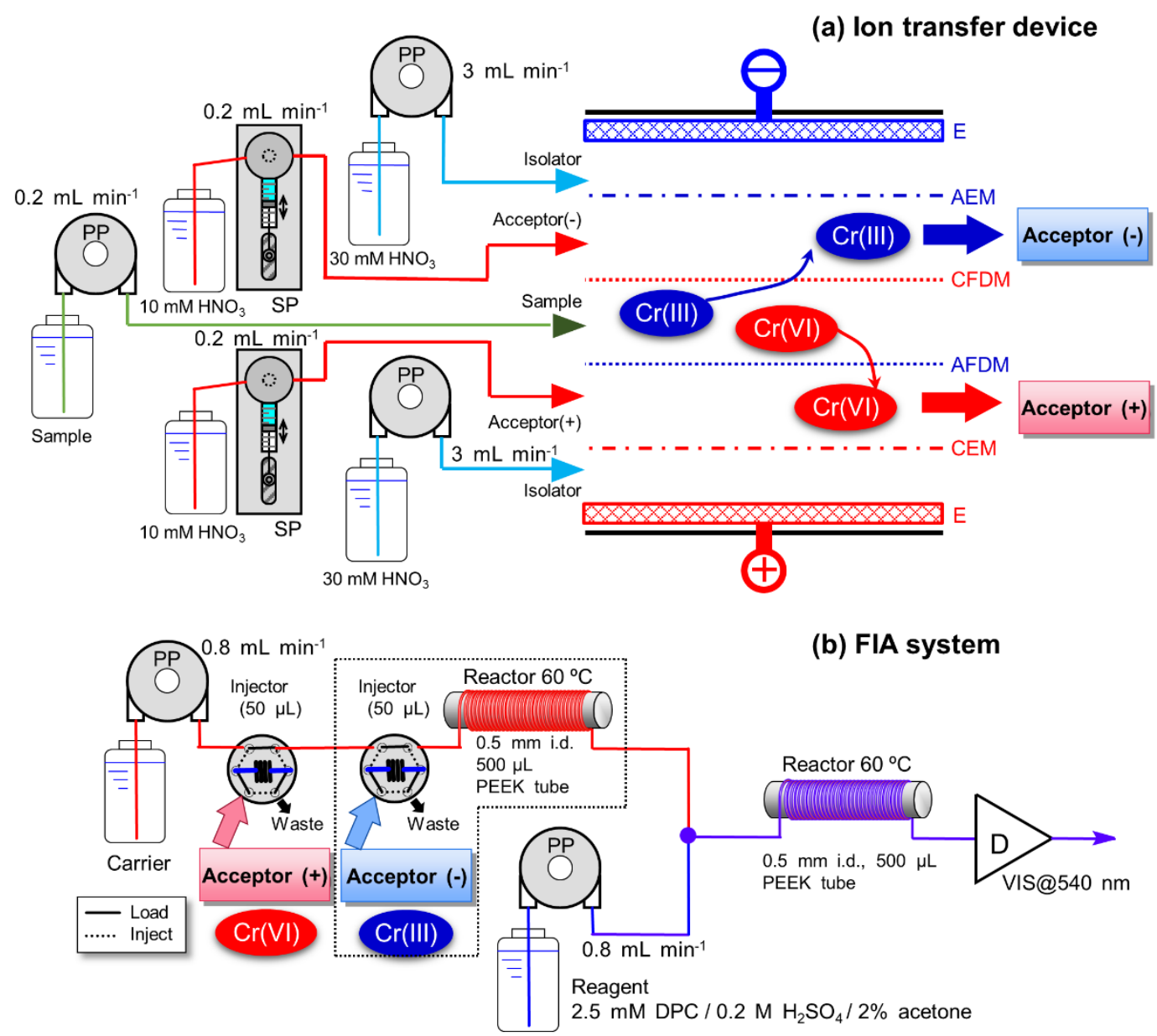

Fig. 1 Schematic diagram for the flow system. PP: peristaltic pump, SP: syringe pump, E: electrode, AEM: anion exchange membrane, CFDM: cation exchange functional group introduced dialysis membrane, AFDM: anion exchange functional group introduced dialysis membrane, FIA: flow injection analysis, D: Detector 


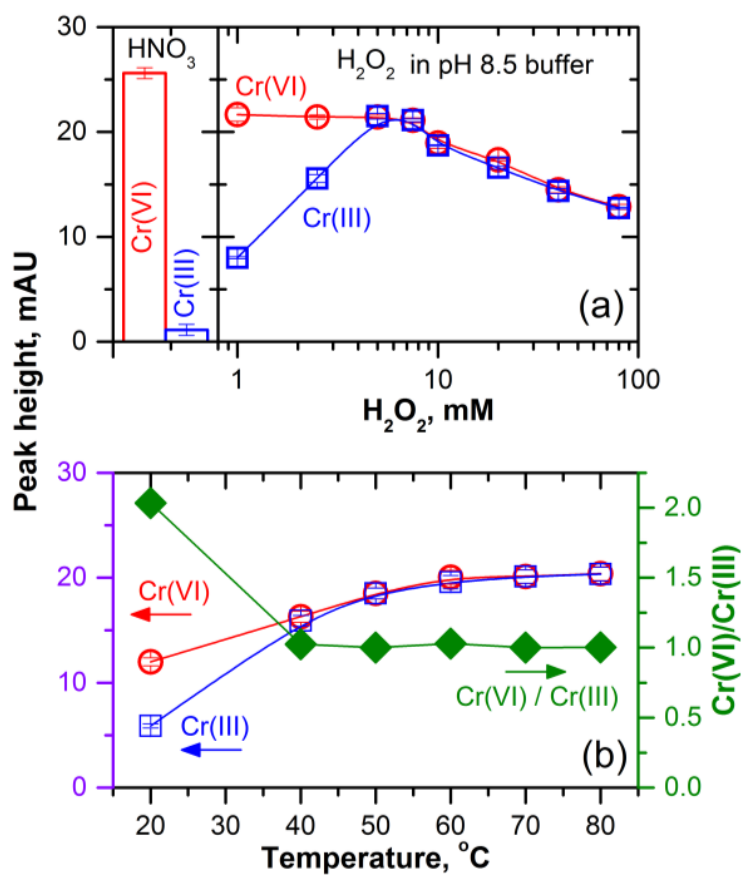

Fig. 2. Effect of $\mathrm{H}_{2} \mathrm{O}_{2}$ concentration (a) and reactor temperature (b). The left panel of (a) shows 10 $\mathrm{mM} \mathrm{HNO} 3$ as carrier without addition of $\mathrm{H}_{2} \mathrm{O}_{2}$. The temperature and $\mathrm{H}_{2} \mathrm{O}_{2}$ concentration for (a) and (b) were $60^{\circ} \mathrm{C}$ and $7.5 \mathrm{mM}$, respectively. The concentration of test solutions was $50 \mu \mathrm{g} \mathrm{L}^{-1}$. 

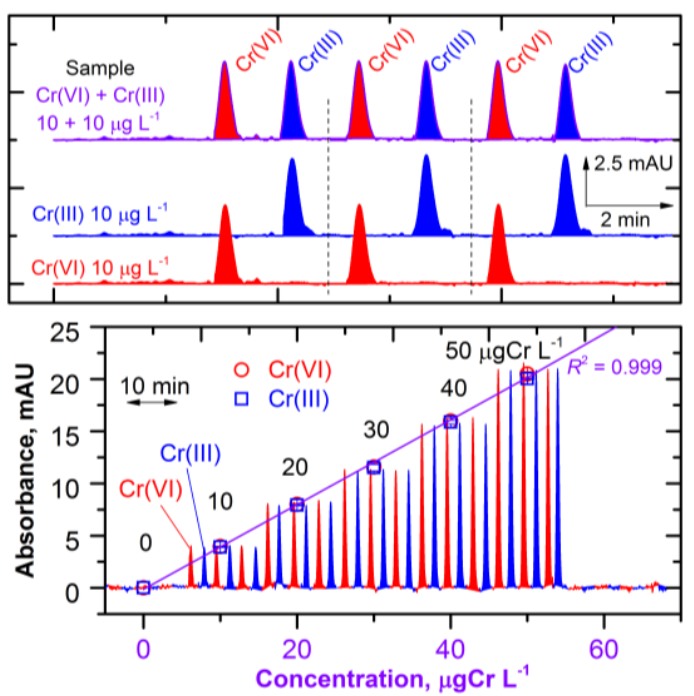

Fig. 3 Response charts and calibration curves obtained with ITD separation and DPC based FIA system 


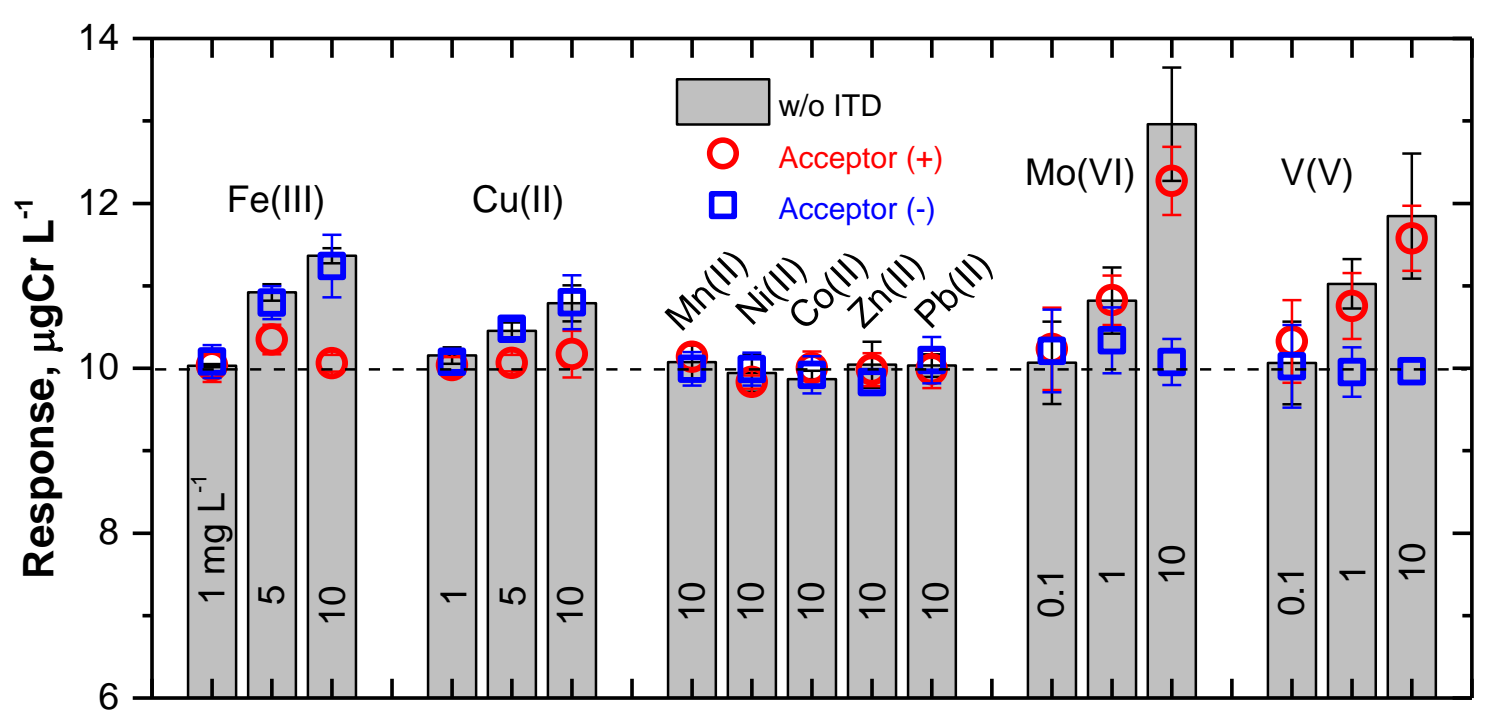

Fig 4. Interference from co-existing ions on the determination of $10 \mu \mathrm{g} \mathrm{L}^{-1}$ of $\mathrm{Cr}(\mathrm{III})$ and $\mathrm{Cr}(\mathrm{VI})$. The direct was obtained without ITD separation and $10 \mu \mathrm{g} \mathrm{L}^{-1}$ of $\mathrm{Cr}(\mathrm{VI})$ was determined. Acceptor $(+)$ and (-) were obtained with ITD separation and stand for cathode and anode sides, respectively. 

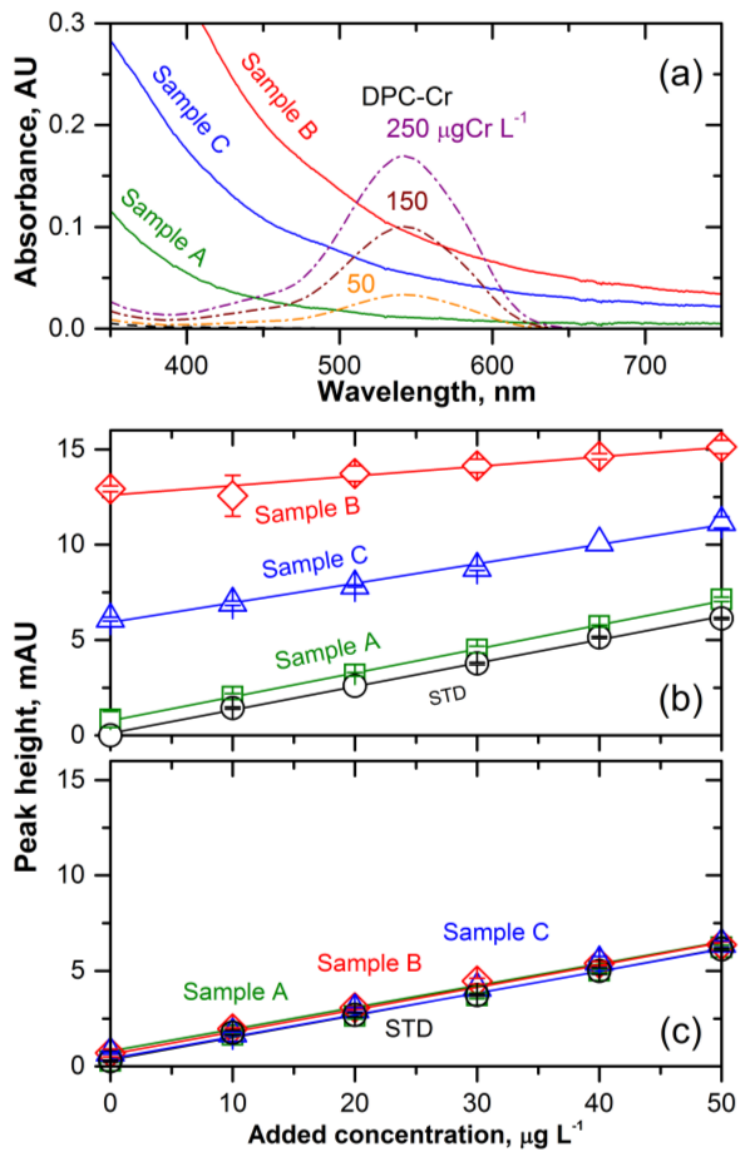

Fig. 5. Spectral absorption of samples and DPC reaction products and standard addition results for soils extracts. (a) Spectra of soil extracts and DPC-Cr products, and (b) standard addition results without ITD separation and (c) with ITD separation. 


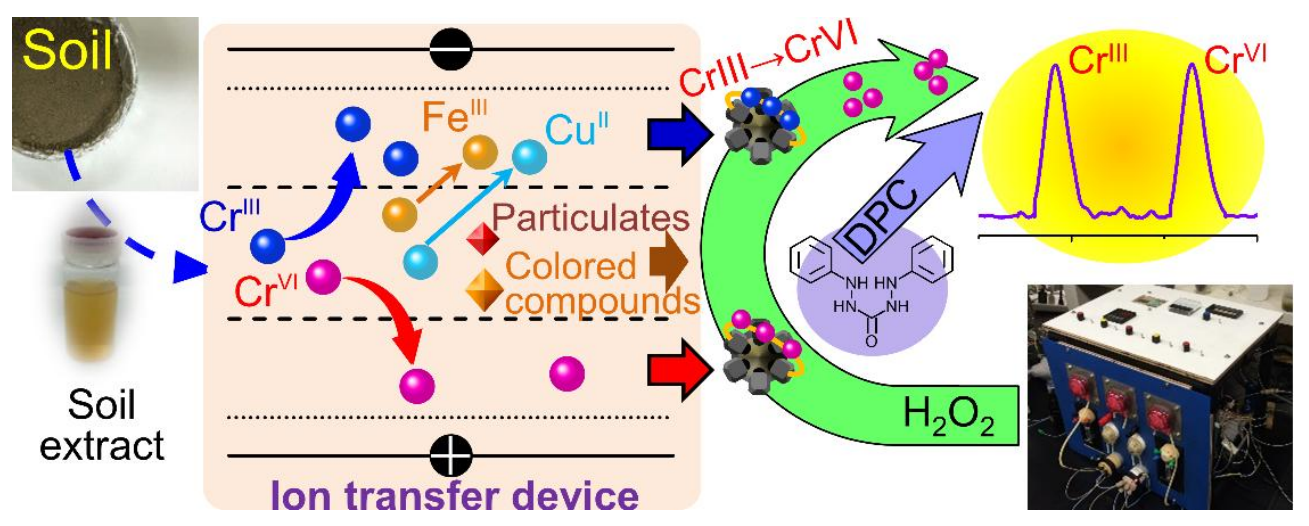

